\title{
Study of physico-chemical characteristics of nickel insertion in
} phosphogypsum

\author{
H. Nafai*, G. Lamzougui, A. Bouhaouss and R. Bchitou* \\ Department of Chemistry, Nanostructures Laboratory, Process Engineering and Environment, Faculty of \\ Sciences, University Mohammed V, Rabat, Morocco \\ E.mail: nafai-smc2011@hotmail.fr / bchitou@hotmail.com
}

\begin{abstract}
The main purpose of this work is study the influence of the insertion metal ions $\mathrm{Ni}$ (II) in the phosphogypsum produced by sulfuric acid attack of tricalcium phosphate. Indeed, the maximum content of heavy metals calcium sulfate that can absorb was determined. The added ions are $\left(\mathrm{NiCl}_{2}, 6 \mathrm{H}_{2} \mathrm{O}\right)$ with mass concentrations ranging from $5 \%$ to $50 \%$. The samples prepared were characterized by various methods, such as X-ray diffraction (XRD), infrared spectroscopy and inductively coupled plasma atomic emission spectroscopy (ICP-AES). The results of this study showed that the limit of insertion of metal cations in calcium sulfate is limited to $30 \%$ for nickel.
\end{abstract}

Keywords: Phosphogypsum; Nickel; Insertion; XRD; IR ; ICP-AES

\section{INTRODUCTION}

The increasing worldwide interest carried to the environmental preservation, attracted much industrialists attention to find a technical means to reduce or to valorize the solid waste. Indeed, phosphate industry, particularly the production of phosphoric acid, rejects phosphogypsum which is rich in calcium sulfate and contains heavy metals such as nickel ${ }^{1-3}$.

The environmental problems of phosphogypsum are directly related to the rock phosphate. In this context, we realized this reaction with $\mathrm{Ca}_{3}\left(\mathrm{PO}_{4}\right)_{2}$ to avoid any interaction with heavy metals in order to find the insertion capacity of these metals in phosphogypsum.

In fact, the tricalcium phosphate structure $\mathrm{Ca}_{3}\left(\mathrm{PO}_{4}\right)_{2}$ is able to accept a large number of cationic substitutes ${ }^{4-7}$. This can significantly change their physical and chemical properties. Indeed, the $\mathrm{Ca}^{2+}$ ions can be exchanged with divalent ions such as $\mathrm{Sr}^{2+}, \mathrm{Cd}^{2+}, \mathrm{Ba}^{2+}, \mathrm{Cu}^{2+}, \mathrm{Ni}^{2+}$ and $\mathrm{Co}^{2+}$. These substitutions have been the subject of some research projects in the field of heterogeneous catalysis and wastewater treatment ${ }^{8-14}$.

There are several analytical methods which can be used on sample characterization. To perform the determination of chemical elements usually X-ray diffraction, infrared spectroscopy and inductively coupled plasma . There are several strategies to digest solid samples, however, in some cases the decomposition does not occur in micro level, so the recovery of the total concentration of selected elements is not adequate. To overcome this difficulty it is fundamental to do experimental tests using distinct accessories and/or reagents. After the spectrometry analysis on the digested sample, the total content of the chemical element can be obtained ${ }^{15}$.

In this work is to study the physical and chemical characteristics of the insertion of nickel in the calcium sulfate in order to determine the maximum levels of these metals can be absorb by calcium sulfate. This was realized by following the insertion by the X-ray diffraction, infrared spectroscopy and atomic emission spectrometry with inductively coupled plasma (ICP-AES).

\section{EXPERIMENTAL}

\subsection{Materials and Methods}

The phosphogypsum was prepared at $80^{\circ} \mathrm{C}$, and after 1 hour 30 minutes of maturation, the hot solution is filtered to recuperate the phosphoric acid. Thereafter, the solid was washed with hot bidistilled water and pure acetone. It is finally dried at $80^{\circ} \mathrm{C}$.

The overall reaction equation:

$$
\underset{\text { ricalcium phosphate }}{\mathrm{Ca}_{3}\left(\mathrm{PO}_{4}\right)_{2}}+3 \mathrm{H}_{2} \mathrm{SO}_{4}+\underset{\mathrm{H}}{2} \rightarrow \underset{\substack{\text { Phosphogypsum } \\ \text { Phaso }}}{3\left(\mathrm{CaSO}_{4}, 2 \mathrm{H}_{2} \mathrm{O}\right)}+2 \mathrm{H}_{3} \mathrm{PO}_{4}
$$

This reaction is carried out in two steps:

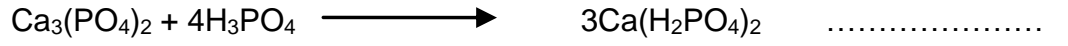

$$
\begin{aligned}
& 3 \mathrm{Ca}\left(\mathrm{H}_{2} \mathrm{PO}_{4}\right)_{2}+3 \mathrm{H}_{2} \mathrm{SO}_{4}+6 \mathrm{H}_{2} \mathrm{O} \longrightarrow 3\left(\mathrm{CaSO}_{4}, 2 \mathrm{H}_{2} \mathrm{O}\right)+6 \mathrm{H}_{3} \mathrm{PO}_{4} \text {. }
\end{aligned}
$$

The same reaction is performed by adding the cations $\mathrm{Ni}$ (II) with mass concentrations ranging from $5 \%$ to $50 \%$ according to the following reactions:

$$
\mathrm{Ca}_{3}\left(\mathrm{PO}_{4}\right)_{2}+\mathrm{xNi}^{2+} \longrightarrow \mathrm{Ca}_{3-\mathrm{x}} \mathrm{Ni}_{\mathrm{x}}\left(\mathrm{PO}_{4}\right)_{2}+\mathrm{xCa}^{2+}
$$


The fixation mechanism is described as the insertion of the metal on the surface of tricalcium phosphate, followed by substitution with cationic calcium ${ }^{16}$. The metal introduction takes place in the second reaction (2)

\section{RESULTS AND DISCUSSION}

\subsection{Analysis of ionic groups by infrared spectroscopy in the case of nickel}

The results of the IR spectroscopy analysis of calcium sulfate prepared in the presence of nickel contents ranging from $5 \%$ to $50 \%$ are shown in the following figure 1 .

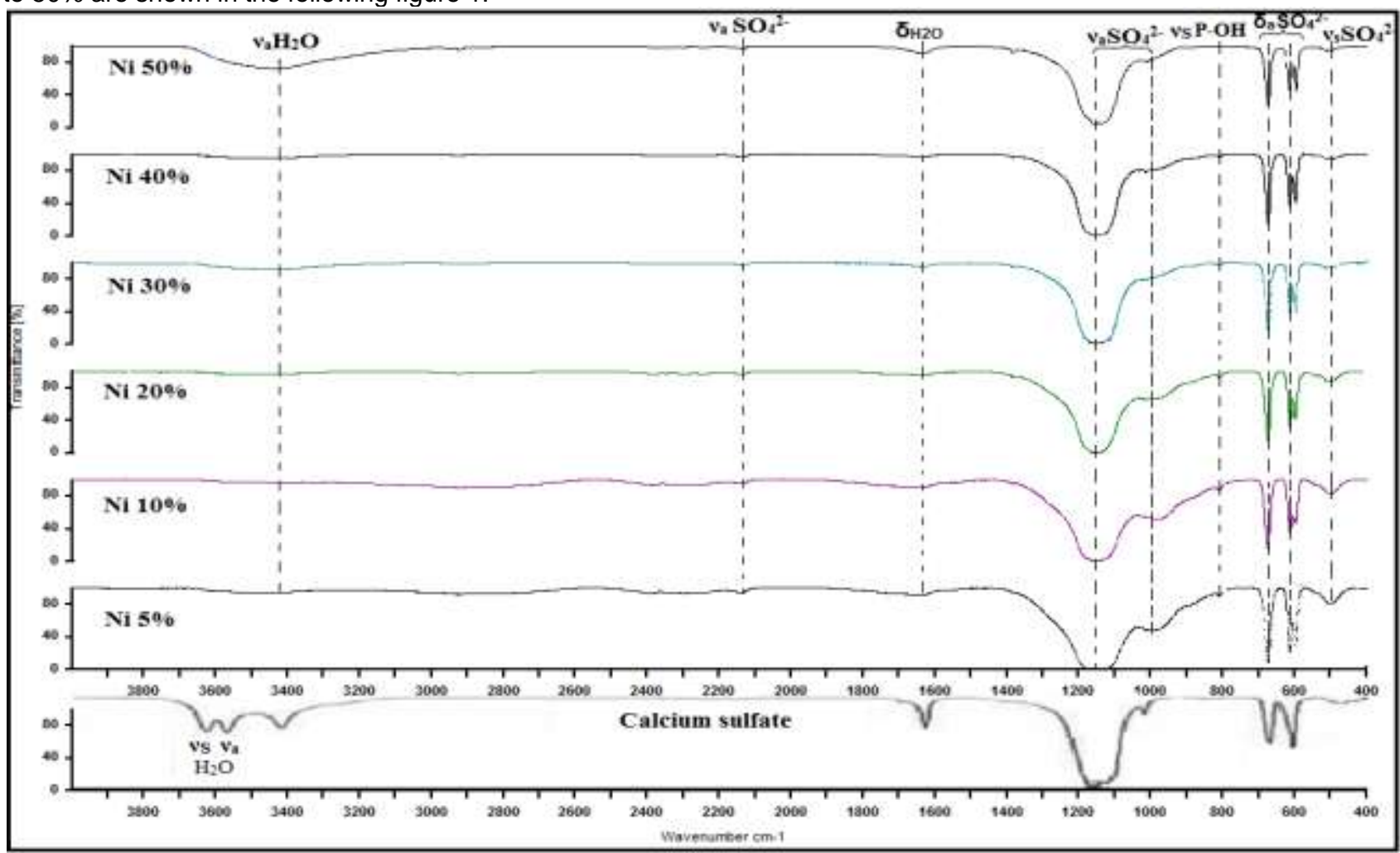

Fig 1: Infrared absorption spectra of solid samples in the presence of nickel

Analysis of these infrared absorption spectra allowed the characterization of products formed in phosphoric medium. Band positions are shown in Table 1.

Table1. Assignment of characteristic bands of different obtained solids

\begin{tabular}{|c|c|c|c|}
\hline $\mathrm{Ca}_{1-\mathrm{x}}-\mathrm{Ni}_{\mathrm{x}}-\mathrm{SO}_{4}, 2 \mathrm{H}_{2} \mathrm{O}$ & characteristic bands & spectral range $\left(\mathrm{cm}^{-1}\right)$ & Phase concerned \\
\hline \multirow[t]{7}{*}{$x=0$} & $\delta_{\mathrm{a}} \mathrm{SO}_{4}$ & 680 et 600 & $\mathrm{CaSO}_{4}, 0.5 \mathrm{H}_{2} \mathrm{O}$ \\
\hline & $\mathrm{v}_{\mathrm{a}} \mathrm{SO}_{4}$ & 2132 et 1153 & $\mathrm{CaSO}_{4}, 2 \mathrm{H}_{2} \mathrm{O}$ \\
\hline & $\delta \mathrm{H}_{2} \mathrm{O}$ & 1620 & \\
\hline & $\mathrm{v}_{\mathrm{s}} \mathrm{HPO}_{4}$ & 850 & $\mathrm{CaHPO}_{4}, 2 \mathrm{H}_{2} \mathrm{O}$ \\
\hline & $\mathrm{v}_{\mathrm{a}} \mathrm{HPO}_{4}$ & 980 & \\
\hline & $\mathrm{v}_{\mathrm{s}} \mathrm{H}_{2} \mathrm{O}$ & 3406 & \\
\hline & $\mathrm{v}_{\mathrm{a}} \mathrm{H}_{2} \mathrm{O}$ & 3620 et 3550 & \\
\hline \multirow[t]{7}{*}{$5 \% \leq x \leq 50 \%$} & $\mathrm{v}_{\mathrm{S}} \mathrm{SO}_{4}$ & $525-512$ & $\mathrm{CaSO}_{4}, 2 \mathrm{H}_{2} \mathrm{O}$ \\
\hline & $\delta_{\mathrm{a}} \mathrm{SO}_{4}$ & 673 et 612 & $\mathrm{NiSO}_{4}$ \\
\hline & $\mathrm{v}_{\mathrm{a}} \mathrm{SO}_{4}$ & 2134 et 1154 & \\
\hline & $\delta \mathrm{H}_{2} \mathrm{O}$ & 1630 & \\
\hline & $\mathrm{v}_{\mathrm{S}} \mathrm{HPO}_{4}$ & 808 & $\mathrm{CaHPO}_{4}, 2 \mathrm{H}_{2} \mathrm{O}$ \\
\hline & $\mathrm{v}_{\mathrm{a}} \mathrm{HPO}_{4}$ & 1012 & \\
\hline & $\mathrm{v}_{\mathrm{s}} \mathrm{H}_{2} \mathrm{O}$ & 3410 & \\
\hline
\end{tabular}


Infrared absorption spectra of the different solid samples are recorded in the area ranging from 4000 to $400 \mathrm{~cm}^{-1}$ in a percentage range of transmission equal to 40. Figure 2 shows a comparison of infrared spectra of solid solutions obtained with calcium sulfate. The observed bands at $808 \mathrm{~cm}^{-1}$ is probably due to the vibrations of $\mathrm{HPO}_{4}{ }^{2-}$ which absorb in the same region. The intensity of this band varies with the rate of nickel incorporated into the calcium sulfate crystal.

From the quantities of nickel less than $30 \%$, the spectra have the same shape as that of calcium sulfate, with a slight shift of some vibration bands. This discrepancy is probably due to the existence of exchange reactions between $\mathrm{Ca}$ (II) and $\mathrm{Ni}(\mathrm{II})$. Over $30 \%$ of $\mathrm{Ni}$, we notice the disappearance of the bands of the P-O binding. This explains why the insertion of nickel is stopped. The observed band at $3406 \mathrm{~cm}^{-1}$ is usually attributed to symmetric stretching vibrations of $\mathrm{OH}^{-}$ions. This suggests that the introductions of $\mathrm{Ni}(\mathrm{II})$ ions significantly alters the intensity of this band and of that corresponding to the $\mathrm{OH}$ groups and the $\mathrm{Ni}$ ions are exchanged as $\left(\mathrm{NiSO}_{4}\right)$

\subsection{Quantitative phase analysis by XRD in the case of nickel}

The obtained X-ray diffraction patterns of the series of solid samples prepared in the presence of varying nickel contents from 0 to $50 \%$ are shown in figure 2 .

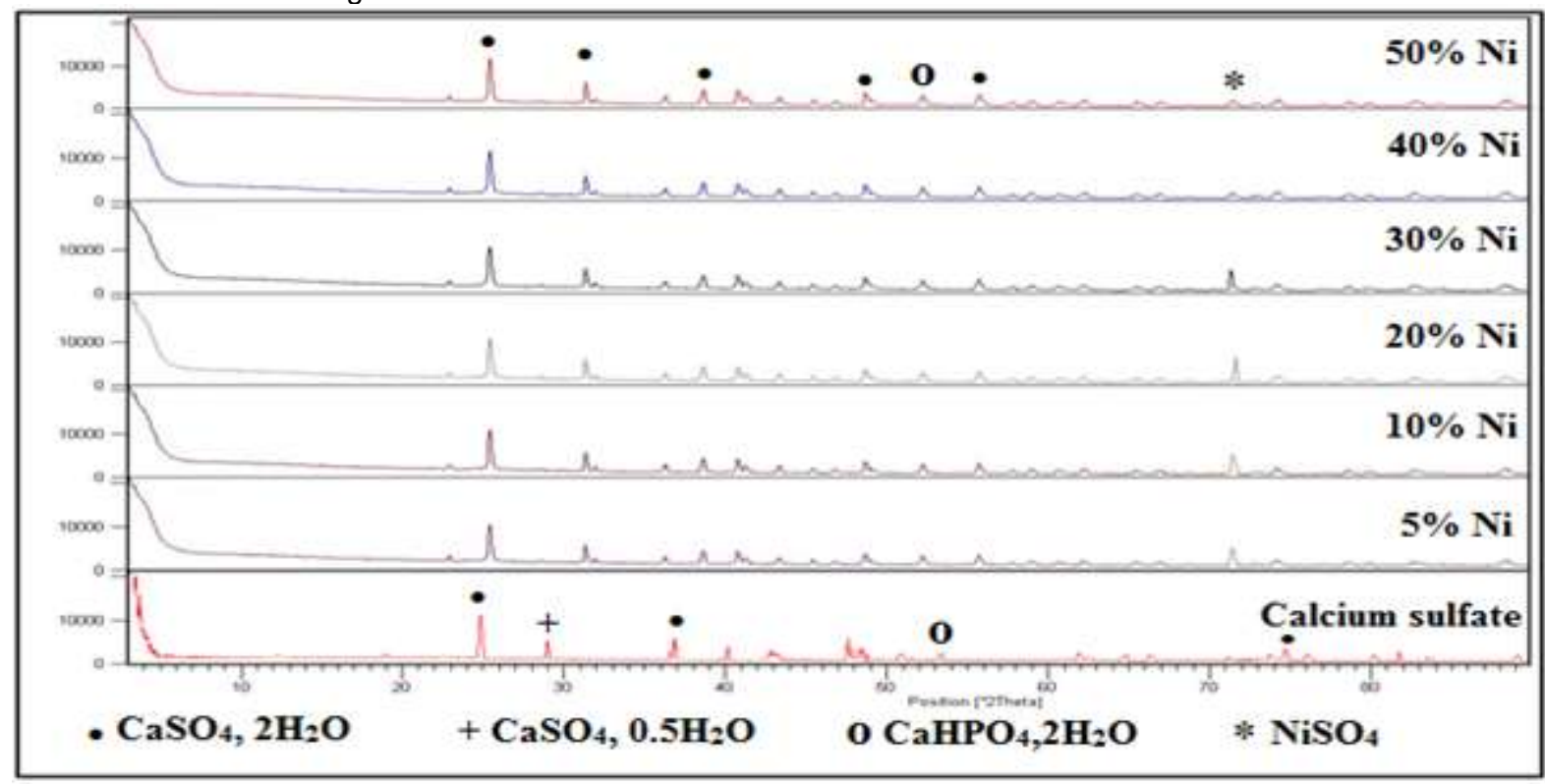

Fig 2: Diffraction patterns of X-rays of calcium sulfate prepared with varying nickel contents

The X-ray diffraction patterns (figure 2) reveal the presence of $\left(\mathrm{CaSO}_{4}, 2 \mathrm{H}_{2} \mathrm{O}\right),\left(\mathrm{CaSO}_{4}, 0.5 \mathrm{H}_{2} \mathrm{O}\right),\left(\mathrm{CaHPO}_{4}, 2 \mathrm{H}_{2} \mathrm{O}\right)$, and $\left(\mathrm{NiSO}_{4}\right)$ phases. A perfect similarity is observed between these diffraction patterns of $\mathrm{X}$-rays $(5 \%$ to $50 \%$ mass percentage of nickel) with a small displacement of the peaks. From a concentration of $5 \%$, there is the appearance of the peak characteristic of the presence of nickel sulfate $\left(\mathrm{NiSO}_{4}\right)(2 \theta=72)$. The intensity of this peak increases with progressive addition of nickel.

In Figure 2, we note that when the nickel content reached a maximum of $30 \%$, the peak intensity decreases.

\subsection{Analysis by inductively coupled plasma atomic emission spectrometry of phosphoric acid}

To test the insertion system, the following parameters were used: insertion efficiency of the system ( percentage of nickel

(II) biosorption) indicating the percentage of exchanging metal ions relative to the initial amount $\mathrm{C}_{\mathrm{i}}$, and insertion capacity

$\mathrm{C}_{\mathrm{f}}$. The percentage of nickel (II) biosorption was calculated by using Equation 1.

$$
\text { percentage of nickel } \left.(I I) \text { biosorption }=\frac{\left(C_{i}-C_{f}\right)}{C_{i}} * 100 \% \quad \text { (Equation } 1\right)
$$

where $C_{i}=$ initial nickel (II) concentration (\%), $C_{f}=$ final concentration of nickel (II) concentration (\%)

This result is confirmed by chemical analysis of phosphoric acid solutions by analyzing the residual amount. The amounts are summarized in the following table: 
Table2. Results of chemical analysis of phosphoric acid containing different contents of nickel (\%Mass: percent by mass)

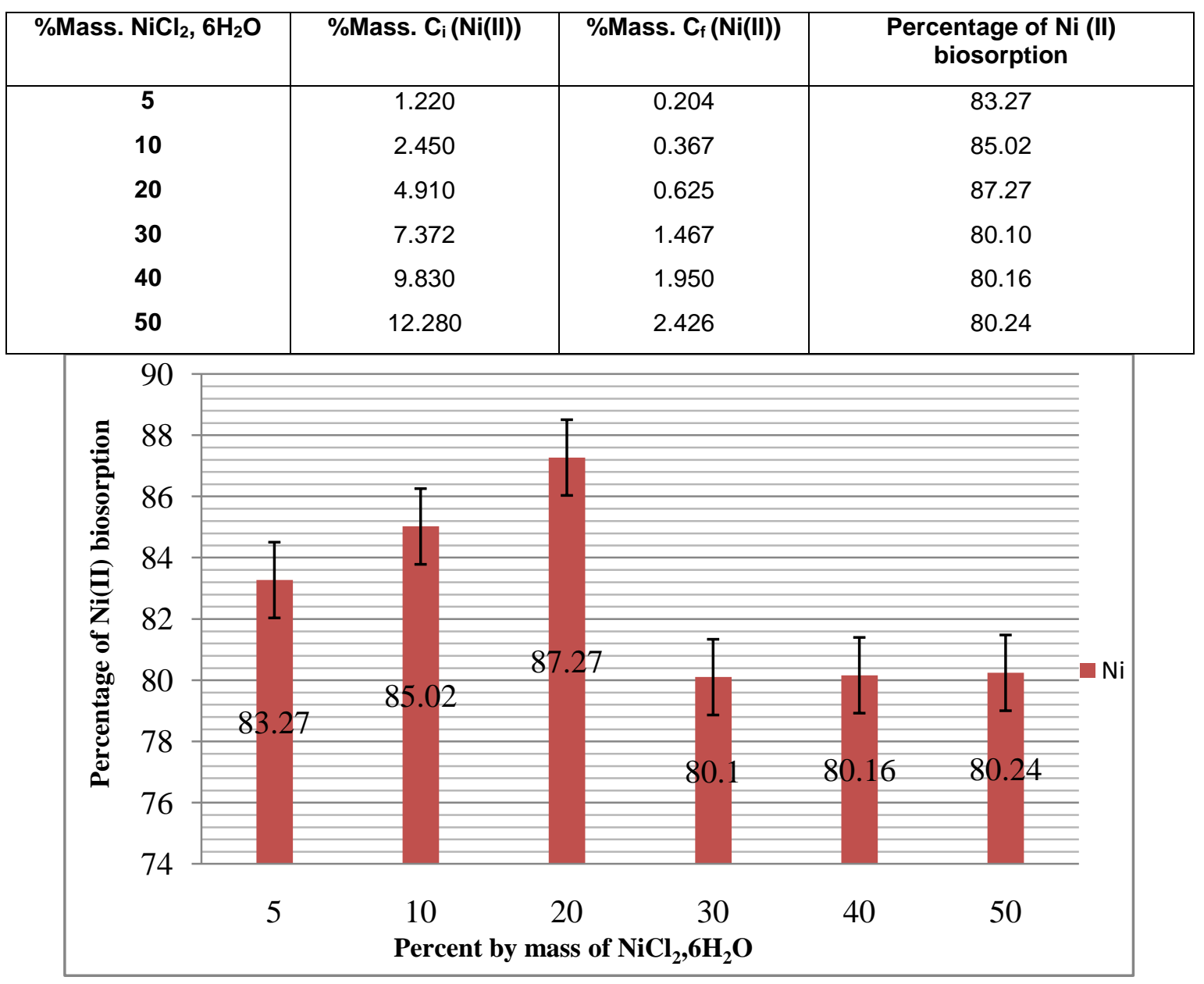

Fig 3: Percentage of changes as a function of percent by mass

From these results, it is obvious that the nickel ions content increases in the recovered acid, when this content is increased in the reactor solution from $5 \%$ to $50 \%$, this content does not exceed the limit in the calcium sulfate which is of the order of $30 \%$ (\% Rem $=80 \%)$.

\section{CONCLUSION}

In this work, we were interested in the exchange of the ions $\mathrm{Ca}^{2+}$ by nickel in the calcium sulfate. The results of infrared absorption spectroscopy and the X-ray diffraction of the all solids show that the calcium ion exchange with nickel in the tricalcium phosphate leads to a modification on the characteristics of calcium sulfate with a displacement and enlargement of some bands of vibration. All chemical analysis results show that the content of nickel and ions increases regularly in the produced acid, when the content of reactant solutions increases. Also, these results explain clearly the presence of the phases $\left(\mathrm{NiSO}_{4}\right)$, and show that the insertion of the metal cations obtained in calcium sulfate is limited at $30 \%$ of the nickel. The results of this study explain that the calcium sulfate prepared characteristics are favourable for removal metal cations $\mathrm{Ni}(\mathrm{II})$ from the aqueous solution and wastewater.

\section{REFERENCES}

[1] López, R. P., Álvarez-Valero, A. M, Nieto, J. M., Perez-Lopez, R., Alvarez-Valero, A. M., and Nieto, J. M. 2007. Changes in mobility of toxic elements during the production of phosphoric acid in the fertilizer industry of Huelva (SW Spain) and environmental impact of phosphogypsum wastes. J. Hazard. Mater. $148,745-750$.

[2] Singh, N.B., and Middendorf, B. 2007. Calcium sulphate hemihydrate hydration leading to gypsum crystallization. Prog.Cryst.Growth.Ch. 53, 57-77.

[3] Hanna, A. A., Akarish, A. I. M., and Ahmed, S. M. 1999. Phosphogypsum: Part I : Mineralogical, Thermogravimetric, Chemical and Infrared Characterization. J. Mater. Sci. Technol. 15 , 431-434. 
ISS N $2321-807 x$

Volume $12 \mathrm{Number} 6$

Journal of Advances in Chemistry

[4] Tayibi, H., Choura, M., López, F. A., Alguacil, F. J., and López-Delgado, A. 2009. Environmental impact and management of phosphogypsum. J. Environ. Manage. 90, 2377-2386.

[5] Müller, M., Fischer, H. B., Hummel, H. U., and Stark, J. 2004.Gypsum Crystals and their Morphology. Chemine Technologija. 3, 43-49.

[6] Min, Y., Jue shi, Q., Zhi, W., and Yubin, H. 2007. J. Mater. Rev. 6, 104-106.

[7] Illera, V., Garrido, F., Serrano, S., and Garcia Gonzalez, M. T. 2004 .Immobilization of the heavy metals Cd, Cu and $\mathrm{Pb}$ in an acid soil amended with gypsum-and lime-rich industrial by-products . J. Soil Sci. 55 , 135-145.

[8] Beedle, A. M., Hamid, J., and Zamponi, G. W. 2002. Inhibition of transiently expressed low-and high-voltageactivated calcium channels by trivalent metal cations. J. Membr. Biol. 187, 225-238.

[9] Hong-yi, J.,and Tao, L. 2004. J. Wuhan Univ. Technol. 1 , 8

[10] Garg, U. K., Kaur, M. P., Garg, V. K., and Sud, D. 2007. Removal of hexavalent chromium from aqueous solution by agricultural waste biomass. J. Hazard. Mater. 140, 60-68.

[11] Lansman, J. B. 1990. Blockade of current through single calcium channels by trivalent lanthanide cations. Effect of ionic radius on the rates of ion entry and exit. J. Gen. Physiol. 95, 679-696.

[12] Boisvert, J-P., Domenech, M., Foissy, A., Persello, J., and Mutin, J-C .2000. Hydration of calcium sulfate hemihydrate (CaSO4.1/2H2O) intogypsum (CaSO4.2H2O): the influence of the sodium poly(acrylate)/surface interaction and molecular weight. J Cryst Growth. 220,579-591.

[13] Pan, Y., and Fleet, M. E. 2002. Compositions of the apatite-group minerals: substitution mechanisms and controlling factors. Rev. Mineral. Geochem. 48, 13-49.

[14] Kontrec, J., Kralj, D., and Brecevic, L. 2002. J. Prog. Cryst. Growth. Ch. 240, 203-211.

[15] Gennari, R F., Garcia, I., Medina, N H., and Silveira, M G.,. 2011 . Phosphogypsum analysis: total content and extractable element concentrations. International Nuclear Atlantic Conference. 978-85-99141-04-5. p.2

[16] Cao, X., Ma, L. Q., Rhue, D. R., and Appel, C. S. 2004. Mechanisms of lead, copper, and zinc retention by phosphate rock. Environ pollut. 131, 435-444. 